\title{
A Comparison Investigation into Analysis Methods to Determine the Buckling Capacity of South African Cold-Formed Steel Lipped Channel Sections
}

\author{
Johan van Vuuren ${ }^{1}$, Jeffrey Mahachi ${ }^{2}$ \\ ${ }^{1}$ University of Johannesburg, Johannesburg, South Africa \\ 1johanvanvuuren026@gmail.com; 2jmahachi@uj.ac.za
}

\begin{abstract}
This paper presents a comparison investigation into analysis methods to determine the buckling capacity of South African cold-formed steel lipped channel sections. The research considers the evaluation of buckling capacities of five different column lengths using five different methods: 1. experimental tests; 2. the Direct Strength Method (DSM) as prescribed in SANS 10162-2; 3. Eurocode 3; 4. simplified Finite Element Analysis (FEA), i.e. only beam modelling elements; and 5. finely refined FEA, i.e. plate modelling elements. All columns have a $75 \times 50 \times 20 \times 2.0(\mathrm{~h} \mathrm{x} \mathrm{b} \mathrm{x} \mathrm{c} \mathrm{x} \mathrm{t} \mathrm{mm})$ cold-formed lipped channel cross-section. A comparison of the experimental buckling results to the aforementioned methods shows that the Eurocode 3 and DSM buckling resistance values overestimate the buckling loads by $23.8 \%$ and $12.7 \%$, respectively. For the two Finite Element Model (FEM) buckling analyses; the simplified FEA method yields an overestimation of $76.9 \%$ and the finely refined FEA yields an overestimation of $74.8 \%$. It is recommended that the DSM is used to calculate the buckling resistance of cold-formed lipped channels.
\end{abstract}

Keywords: Buckling, thin-walled, cold-formed, Direct Strength Method, Finite Element Analysis.

\section{Introduction}

For the design of cold-formed steel column sections, Appendix 1 of the North American Specification for the Design of Cold-Formed Steel Structural Members presents the Direct Strength Method (DSM) [1]. This method was introduced in 2004 and integrates existing code design procedures with the distinctive behaviour of structural thin-walled steel [2]. The DSM has furthmore been adopted as section 7 of SANS 10162-2: Cold-formed steel structures design code [3]. West-Russell et al. [4] assessed the inherent reliability of SANS 10162-2 codes for cold-formed lipped channel steel columns using the Direct Strength Method (DSM). In the study, it was revealed that the buckling resistance of cold-formed steel compression members exhibits a low level of reliability while considering the safety margin presented in SANS 10160-1: Basis of Structural Design codes [5]. Furthermore, it was revealed that the global buckling mode of the column members yields the lowest reliability levels. It was, therefore, recommended that different capacity reduction factors should be applied to each dominating buckling mode and that the DSM replaces the effective width method for the design of cold-formed steel columns.

In a similar study by Bauer [6], it was revealed that the safety margin achieved when using the DSM, as prescribed by SANS 10162-2, to design cold-formed steel structures does not meet the reliability target prescribed by SANS 10160-1. Also, Dundu [7] conducted a study that compared experimental results with the DSM. The research investigated the buckling resistance values of short cold-formed lipped channels. It was found that the code is not conservative enough for the design of structural columns. The history of buckling failure modes for short cold-formed lipped sections (thin-walled steel) is presented by Dundu [7].

The buckling of a structural member is defined as a mode of failure, this is directly linked to the stability of a structure, and if buckling occurs then the member is unstable. The buckling modes of a lipped channel are limited to Local Buckling (LB), Distortional Buckling (DB) and Global buckling (GB). LB is defined as the plate flexural failure of the lip, flange, and web elements when the line junction of both corners does not change as illustrated in Fig. 1 (a). DB occurs at the ultimate failure by the bending of the web in either outward or inward rotational direction as illustrated in Fig. 1 (b) and (c). GB of a compression member does not involve distortion of the cross-section, instead out of plane translation (flexure) and/or rotation (torsion) about the shear centre of the entire cross-section occurs [3]. GB is associated with flexural, torsional, or flexuraltorsional buckling as illustrated in Fig. 1 (d), (e) and (f) respectively. 


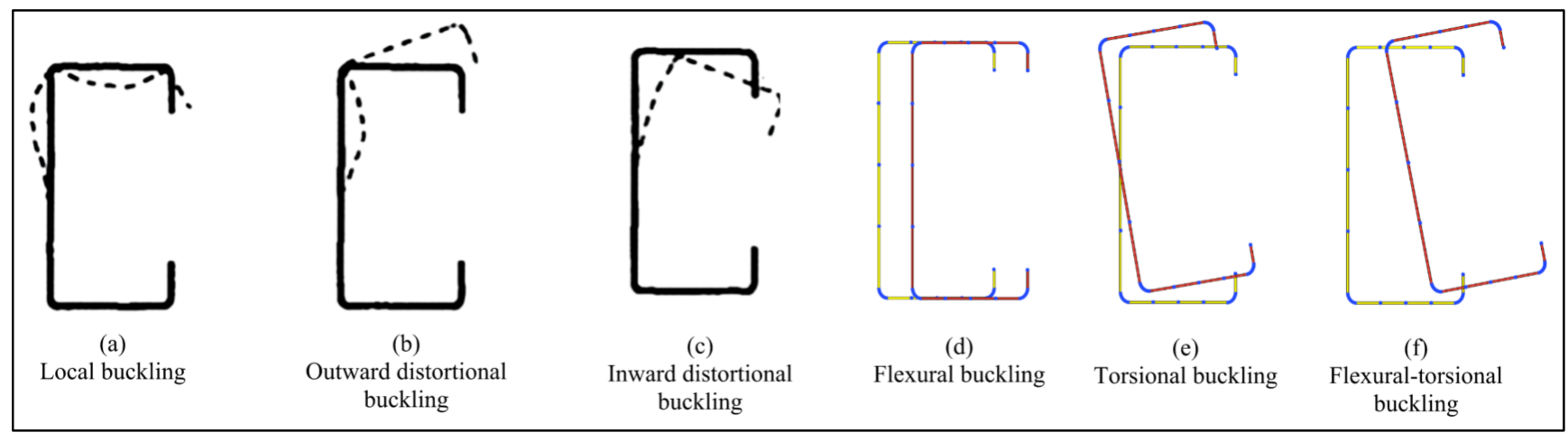

Fig. 1: Buckling modes [4] [7]

With the recent tendency for design codes in South Africa to migrate to the Eurocodes, as seen in the SANS 10160 series, it is reasonable to assume that the SANS 10162-2 might be revised based on the Eurocode 3 design procedures. With the distinctive behaviour of structural thin-walled steel, a more in depth investigation is required. Therefore, this research presents the evaluation and comparison of the buckling capacities for different column lengths using the five different methods: 1. experimental tests; 2. the Direct Strength Method (DSM) as prescribed in SANS 10162-2; 3. Eurocode 3; 4. simplified Finite Element Analysis (FEA); and 5. finely refined FEA. In this research, a typical 75x50x20x2.0 cold-formed lipped channel from The Southern African Steel Construction Handbook [8] was considered for five lengths from $300 \mathrm{~mm}$ to $1500 \mathrm{~mm}$ at $300 \mathrm{~mm}$ increments. The selection was a result of following the optimisation design constraints presented by Ye et al [9]. A comparison of the steel grade was done to match the South African produced steel through SANS 4998 [10], to the EN 1993-1-1 [11] specification.

\section{Direct Strength Method (DSM)}

The DSM is based on the Finite Strip Method (FSM) as a procedural calculation step. The FSM is based on plate buckling theory which yields the buckling modes and accompanying capacities of any thin-walled element under consideration. The detailed description of the calculation procedure for the FSM is presented by Li and Schafer [12].

In order to complete the elastic buckling analysis of the thin-walled steel section under consideration, the CUFSM version 5.04 software was utilized. The program is distributed under the MIT Open Source License and is based on the Matlab runtime engine. The software is freely available at https://www.ce.jhu.edu/cufsm/. The program requires the material and cross-sectional properties as input for the elastic buckling analysis of a specific section. Additionally, the end conditions and the length of the member are required. Through the FSM the CUFSM program generates two results for a specific section; the load-factor versus buckling half-wavelength signature curve and the buckling mode shape of the cross-section. The resultant load-factor vs. half-wavelength curve must be examined to determine the minimum load-factors for each mode shape, this is explained in the Direct Strength Method Design Guide by Schafer [13]. The load-factor is defined as the ratio of the critical design buckling load $\left(N_{c r}\right)$ to the design yield load $\left(N_{y}\right)$ in either bending or compression. The signature curve generated for a specific section under compression loading indicates the LB zone at low half-wavelengths, follow by the DB region and lastly the GB zone at high half-wavelengths. A typical signature curve of a lipped channel steel section subject to compression loads is illustrated in Fig. 2. 


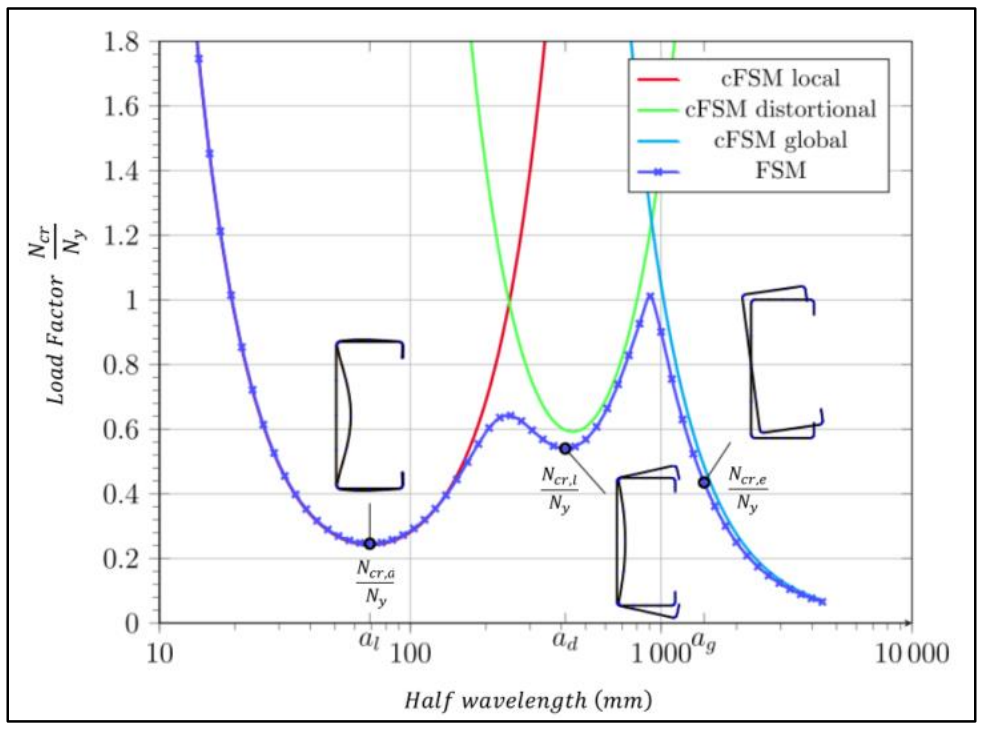

Fig. 2: Typical signature curve [4]

The minima on the curve indicate the lowest load level at which a particular mode of buckling occurs. In Fig. 2 the minima are marked by $N_{c r l} / N_{y}$ and $N_{c r d} / N_{y}$ to indicate the local and distortional load factors respectively. These values are multiplied with the compression yield load $\left(N_{y}\right)$ to determine the resultant local and distortional critical buckling loads. It should be noted that the global critical buckling load is defined by the lesser of the flexural, torsional and flexural-torsional elastic buckling loads and not by a load factor from the signature curve.

\section{Eurocode3}

\subsection{EN 1993-1-3: Local Buckling (LB)}

In order to determine the local buckling, the channel's effective cross-sectional properties are calculated based on the effective widths as per EN 1993-1-5: Plated structural element [14] and presented by Gardner [15]. For the effective area $\left(A_{e f f}\right)$ of a member subject to pure axial compression, the effective web height $\left(h_{e f f}\right)$, flange widths $\left(b_{e f f}\right)$ and lip lengths $\left(c_{e f f}\right)$ are required. To determine the effective values, the method set out in EN 1995-1-5 for plates without long stiffeners is followed. The plate slenderness of each element is obtained which is dependent on the width to thickness ratio, buckling factor and yield strength. The reduction factor for plate buckling $(p)$ varies for internal and external compression plate elements and is applied to the considered dimension by using: $\bar{b}_{\text {eff }}=p \bar{b}$, this yields the effective area $\left(A_{\text {eff }}\right)$. The effective area is applied to the yield strength of the steel for the LB resistance $\left(N_{b, R d}\right)$ as presented in $E N 1993-1-1 ; N_{b, R d}=A_{e f f} f_{y}$.

\subsection{EN 1993-1-3: Distortional Buckling (DB)}

In order to determine the DB resistance of a cold-formed lipped channel steel section, the effective area is determined by using the same method as for the LB, with the exception of the effective lip length. For the effective length of the lipped portion of the channel, EN 1993-1-3 [16] dictates that the buckling factor $\left(k_{\sigma}\right)$ is calculated for a single edge fold stiffener. For the design of compression element with stiffeners, it should be assumed that the stiffener behaves as a compression member with continuous partial restraint with a calculated spring stiffness. The boundary conditions and the flexural stiffness of the adjacent plane elements define the spring stiffness. The spring stiffness for the flange of a lipped channel section is obtained by applying a unit load $u$. The method considers the distance from the web-to-flange junction to the gravity centre of the effective area of the edge stiffener. In order to determine the effective section properties, the reduced effective area is based on a reduced thickness $t_{\text {red }}=t A_{\text {stiff,red }} / A_{\text {stiff }}$ for all the elements. Where the reduced area $\left(A_{\text {stiff,red }}\right)$ and thickness $\left(t_{r e d}\right)$ of the effective stiffener section is obtained by applying a reduction factor $\left(\chi_{d}\right)$. 


\subsection{EN 1993-1-3: Global Buckling (GB)}

In order to determine the GB capacity of cold-formed steel section members subject to axial load, EN 1993-1-3 dictates that elastic critical buckling forces pertaining to the flexural about the major x-x axis $\left(N_{c r, x}\right)$, flexural about the minor $y-y$ axis $\left(N_{c r, y}\right)$, torsional $\left(N_{c r, T}\right)$ and torsional-flexural $\left(N_{c r, T f}\right)$ buckling modes must be calculated. The only difference between the three modes is in the calculation of the elastic critical buckling force which is particular to the buckling mode.

\subsection{EN 1993-1-1: Design Buckling Resistance}

The channel considered in this study is defined as a singly-symmetric Class 4 cross-section. The buckling resistance of a column is defined by $N_{D, R_{d}}=x A_{e f f} f_{y} / \gamma_{m_{1}}$ where $\gamma_{m_{1}}$ is the partial factor for resistance of members to instability. Where $x$ is the reduction factor based on the non-dimensional slenderness ratio $(\lambda)$ and an imperfection factor defined by the buckling curve for C-sections. The non-dimensional slenderness ratio is defined as $\lambda=\sqrt{A_{e f f} f_{y} / N_{c r}}$ for Class 4 crosssections, where $N_{c r}=\min \left\{N_{c r, x} ; N_{c r, y} ; N_{c r, T} ; N_{c r, T F}\right\}$.

\section{Finite Element Analysis (FEA) Modelling}

For each of the specimen lengths, a simplified model that only considers the $\mathrm{x}$ and $\mathrm{y}$ plane was generated as illustrated in Fig. 3 (a). In order to simulate pinned conditions at both ends, the model is restrained only in the x-direction at the top and in the $\mathrm{x}$ and $\mathrm{y}$-directions at the bottom. For this analysis method, only beam elements were used. The beam was sub dived into 10 equal sections and an external vertical $100 \mathrm{kN}$ nodal load in the y-direction was applied at the centroid of the section to simulate the applied axial load. To ensure buckling occurs, the load is applied by load factors starting from 0 to 1.5 with increments of 0.15 . The loading on the column was analysed by means of a non-linear static analysis. In order to interpret the buckling behaviour of the specimen, the horizontal displacement of the middle node was recorded and analysed. The onset of significant displacement (greater than $2 \mathrm{~mm}$ ) in the X-direction (horizontal direction) indicated that the stresses in the steel have exceeded the linear elastic limit and the material has become plastic.

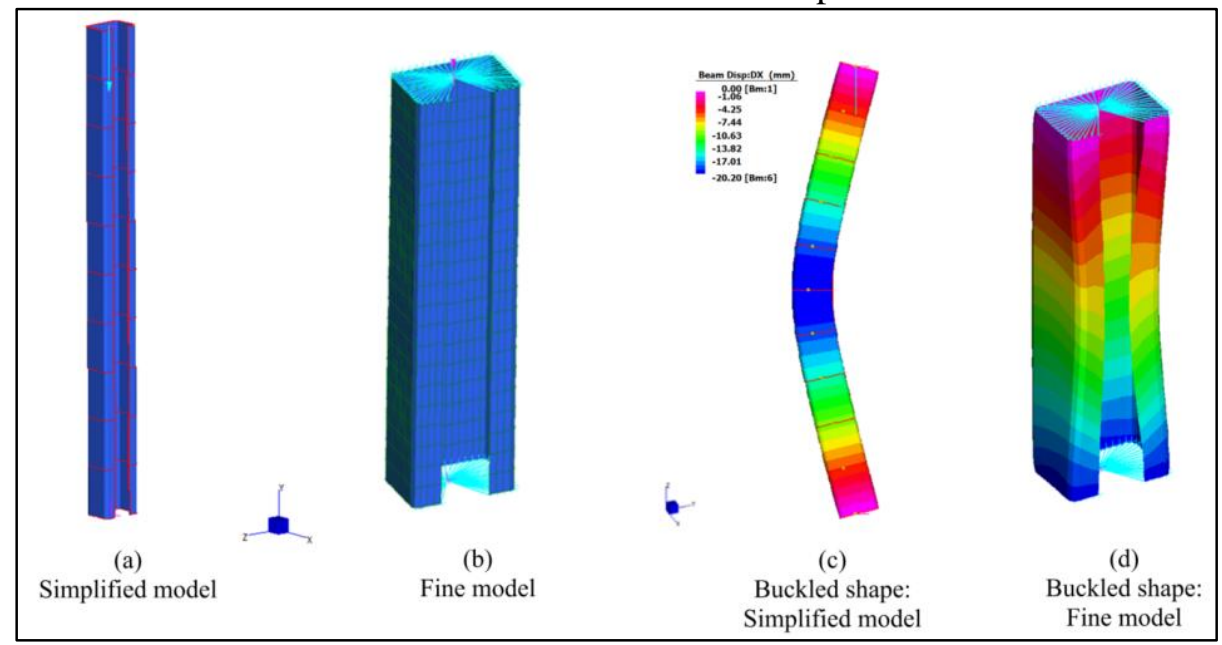

Fig. 3: FEA models and buckled shapes

Finely meshed models were additionally generated and analysed for each of the specimen lengths, these models were constructed with plate elements. The models were constructed with 4 node quadrilateral plate elements sizing $15 \mathrm{~mm}$ x 5 $\mathrm{mm}$, this was selected to adhere to a plate aspect ratio of 3 . All the end nodes were connected to a node positioned at the centroid of the channel with rigid links. The centroid nodes were constrained to be fully fixed against translation and rotation. Fig. 3 (b) illustrates the $300 \mathrm{~mm}$ specimen length fine FEM. The Linear Buckling Solver in Strand 7 was used to determine the first four buckling modes of each model. The non-linear behaviour of the steel is defined in both the simplified and fine 
models by means of the calculated stress-strain curves that were obtained from tensile testing. The channel section is modelled for a geometrically perfect case and a geometrically imperfect case. The first linear buckling mode shape is used as the initial imperfection to account for geometrical imperfections. The enforced compressive axial displacement of $1 \mathrm{~mm}$ is applied by load factors starting from 0 to 50 with increments of 1.0 to ensure that buckling occurs. Both methods of modelling are prescribed by the Strand 7 web notes for buckling analyses (see http://www.strand7.com/webnotes/).

\section{Buckling Test Procedure}

This compressive test setup is based on the layout of the research completed by Dundu [4]. The ends were set to imitate pinned connections, this takes the full length of the compression member as the column's effective length as per SANS 101621 [17]. The load was applied through two plate-ball systems as illustrated in Fig. 4 (a) and (b) for the bottom and top connection respectively. A $500 \times 500 \times 50 \mathrm{~mm}$ plate was positioned at the base of the setup, a $300 \times 300 \times 20 \mathrm{~mm}$ steel plate was used as an isolation pad between the specimen and the spherical steel ball at the bottom end. For the top end, a cylindrical steel section with a diameter of $150 \mathrm{~mm}$ and a depth of $50 \mathrm{~mm}$ was placed between the specimen and the spherical steel ball. Prior to testing, the centres of the plates were marked to align the centroid of the sections. A very small sample size of 5 specimens for experimental tests was obtained through guidelines presented by Holický [18].

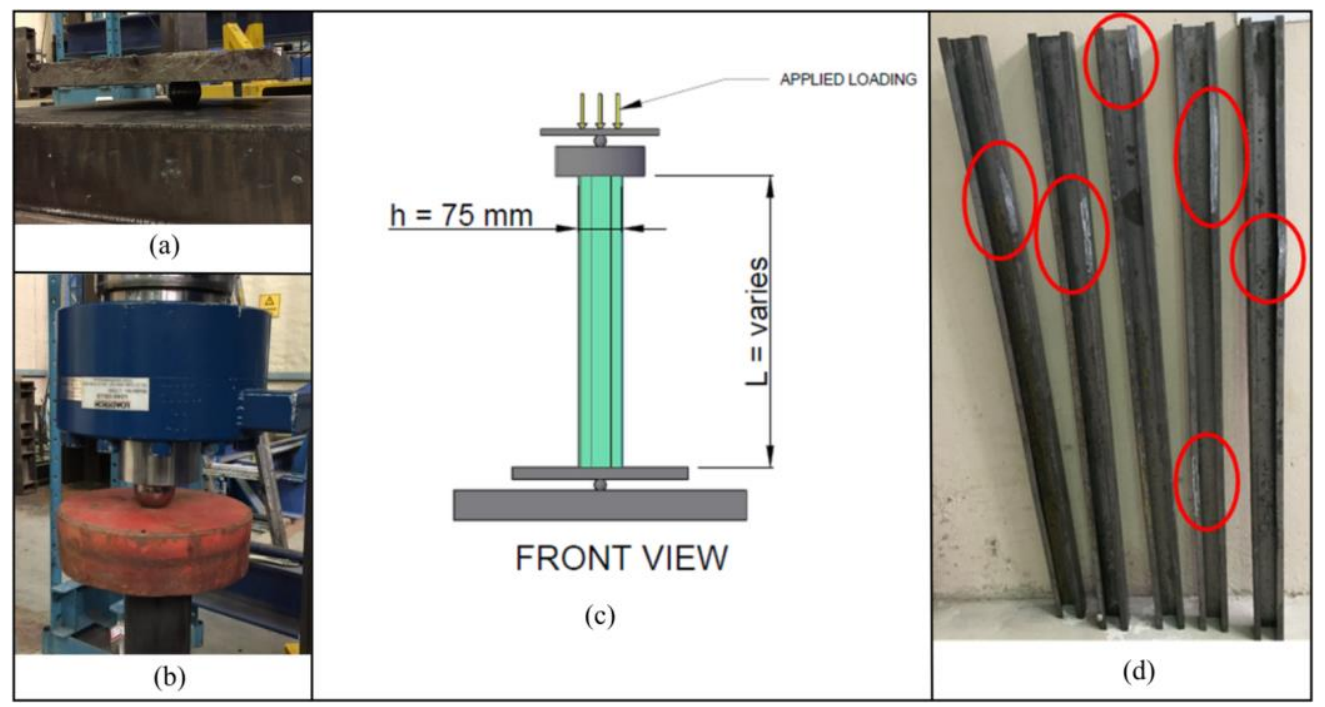

Fig. 4: Experimental end conditions

The ends of the specimens were machined flat, with the load applied at the centroid of the sections. Specimen measurements were completed to record any discrepancies as outlined by Ungermann et al [19]. The tests were completed until the failure which is defined as the axial load where the section has lost all its rigidity and permanent deformation occurs. A $2000 \mathrm{kN}$ Moog testing machine with a loading rate of $3 \mathrm{~mm} / \mathrm{min}$ was used for the experiments. The experimental set-up to determine the buckling loads of the specimens is shown in Fig. 4 (c).

\section{Mechanical Properties}

To determine the mechanical properties of the cold-formed steel sections, tensile testing was completed according to ASTM E8 [20]. The $0.2 \%$ proof yield method was chosen as the appropriate method to determine the yield stress, as used by Shifferaw et al [2]; Weng and Pekoz [21]; and Dundu [4]. The specimens were incrementally axially loaded with a tensile stress load of $30 \mathrm{MPa} / \mathrm{s}$. Both ends of the specimen were completely fixed in translation and rotation. Table 1 presents a summary of the mechanical properties of the steel considered in this investigation. It should be noted that the surfaces of the cut-out specimens were coated with oil directly after it had been machined. This was done to prevent any oxidation of the base metal that can cause discrepancies in the results. 
Table 1: Tensile test results summary

\begin{tabular}{|l|c|c|r|}
\hline \multicolumn{1}{|c|}{ Tensile tests } & $\begin{array}{c}\text { Yield strength }\left(\mathbf{f}_{\mathbf{y}}\right) \\
(\mathbf{M P a})\end{array}$ & $\begin{array}{c}\text { Ultimate strength } \\
\left(\mathbf{f}_{\mathbf{u}}\right) \mathbf{( M P a )}\end{array}$ & $\begin{array}{c}\text { Strain at ultimate } \\
(\mathbf{\%})\end{array}$ \\
\hline Specimen 1 & 292.75 & 372.83 & 22.58 \\
\hline Specimen 2 & 302.03 & 370.42 & 21.90 \\
\hline Specimen 3 & 297.68 & 374.62 & 22.31 \\
\hline Specimen 4 & 300.43 & 372.42 & 23.15 \\
\hline Specimen 5 & 301.22 & 368.33 & 21.66 \\
\hline Mean & $\mathbf{3 0 0 . 3 4}$ & $\mathbf{3 7 1 . 4 5}$ & $\mathbf{2 2 . 2 5}$ \\
\hline
\end{tabular}

The resultant yield strength is $300.34 \mathrm{MPa}$ and the tensile (ultimate) strength of the steel is $371.45 \mathrm{MPa}$. The mean strain at fracture was recorded as at $22.25 \%$ of a gauge length $\left(\mathrm{L}_{\mathrm{o}}\right)$. The resultant stress-strain curve followed the expected shape as presented in [22] and [23]. The elastic modulus for each specimen was calculated as the gradient of the linear elastic region of the graphs yielding $21.81 \mathrm{GPa}$. This value is approximately out by an order of magnitude, i.e. out by a factor of 10 compared to the expected range of 200 to 210 GPa for steel [22] [23]. This discrepancy can be attributed to various causes such as experimental/human error, or poor material quality and elastic modulus values are true. The low elastic modulus will yield unrealistic calculated buckling resistance values and defeat the purpose of this study. Due to this, the Eurocode 3 prescribed values of $210 \mathrm{GPa}$ for the elastic modulus and $81 \mathrm{GPa}$ for the shear modulus were adopted for the calculation of the buckling loads. It should be noted that the results have been reviewed and verified by an external party. Additionally, the suppliers of the tensile testing equipment were contacted and they sent an experienced technician to inspect the equipment, after which the technician confirmed the equipment was calibrated and working correctly. The Ramberg-Osgood stress-strain model as presented by Basan et al [24] and Deolia and Shaikh [25], was adopted to define the steel's mechanical properties for the FEAs.

\section{DSM Results}

Fig. 5 (a), (b) and (c) presents the local, distortional and global buckling load factors respectively, as generated by the CUFSM software. The deformed shapes of the $75 \times 50 \times 20 \times 2.0$ cold-formed lipped channel are also illustrated at the top of the figures.

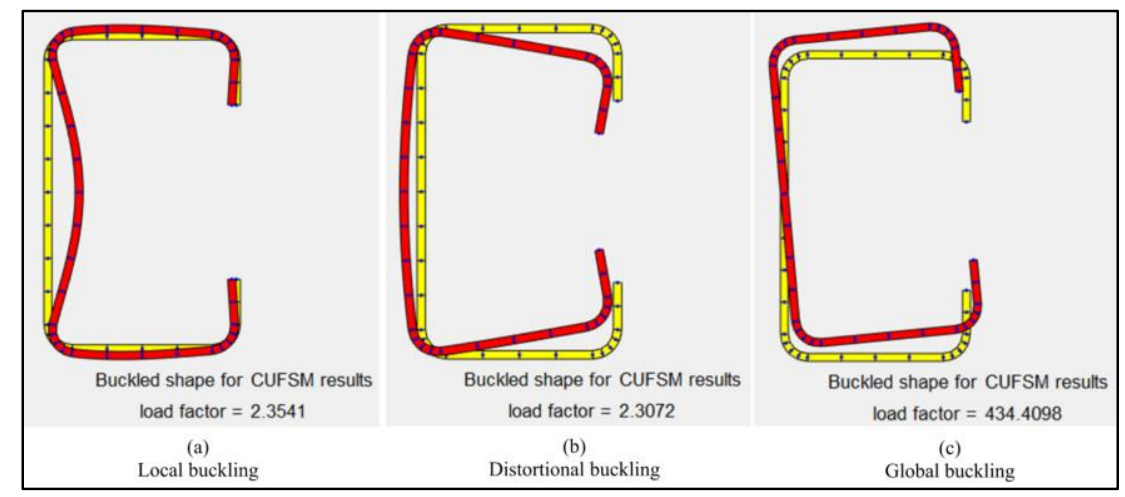

Fig. 5: Buckled shapes

The local and distortional buckling load factors are 2.35 and 2.31 respectively. These load factors were used to determine the local and distortional buckling capacities of the cross-section. The calculated buckling resistance loads for the considered specimen lengths are presented in Table 2. For all the specimen lengths the LB and GB capacities are identical, with higher DB capacities. As such, the GB values are limiting and the resultant resistance values. The calculated buckling resistance for the $300 \mathrm{~mm}, 600 \mathrm{~mm}, 900 \mathrm{~mm}, 1200 \mathrm{~mm}$, and $1500 \mathrm{~mm}$ specimens are $99.52 \mathrm{kN}, 90.45 \mathrm{kN}, 77.61 \mathrm{kN}, 63.56 \mathrm{kN}$, and 50.02 $k N$ respectively. 


\section{Eurocode 3 Results}

The minimum value between the LB, DB and GB is selected as the buckling resistance for each of the experimental lengths. The Eurocode 3 buckling resistance values for the specimens are presented in Table 2 . For all the specimen lengths the LB and DB capacities are identical, with lower GB capacities. The calculated buckling resistance for the $300 \mathrm{~mm}, 600$ $\mathrm{mm}, 900 \mathrm{~mm}, 1200 \mathrm{~mm}$, and $1500 \mathrm{~mm}$ specimens are $116.20 \mathrm{kN}, 102.88 \mathrm{kN}, 85.29 \mathrm{kN}, 66.06 \mathrm{kN}$, and $50.52 \mathrm{kN}$ respectively.

\section{FEA Results}

Typical post buckling horizontal exaggerated deformation shapes for the simplified and fine FEAs are illustrated in Fig. 3 (c) and (d) respectively. The horizontal displacement values illustrated in the figures are irrelevant and are only used to illustrate that the specimens have significantly deformed to indicate buckling. The calculated buckling loads are presented in Table 2. The buckling load for the simplified $300 \mathrm{~mm}$ model is $130 \mathrm{kN}$, this decreases to $110 \mathrm{kN}$ for the $1200 \mathrm{~mm}$ model. The $1500 \mathrm{~mm}$ model yields a greater resultant buckling load of $114 \mathrm{kN}$, this is unexpected, so further investigation was completed by reviewing the graphical representation of the results. The shape confirms the non-linear properties of the models as it follows a horizontally reflected shape of the stress-strain curve used [22][23].

For the finely refined models the results were captured and plotted as the reaction load versus the enforced displacement. The maximum reaction loads from the graphs were interpreted as the buckling load of the analysed columns and are presented in Table 2. There were small differences between the buckling load of the perfect and imperfect models, but overall the imperfect models yielded the lowest resultant load. From this, only the buckling loads of the geometrically imperfect models were used for comparison purposes. The buckling loads calculated from the fine FEA models are $123.0 \mathrm{kN}, 119.27 \mathrm{kN}$, $113.71 \mathrm{kN}, 111.74 \mathrm{kN}$, and $110.0 \mathrm{kN}$ for the $300 \mathrm{~mm}, 600 \mathrm{~mm}, 900 \mathrm{~mm}, 1200 \mathrm{~mm}$, and $1500 \mathrm{~mm}$ specimens respectively.

\section{Buckling Test Results}

Experimental results were processed through statistical inference presented in Walpole [26]. Fig. 4 (d) illustrates the buckled specimens for the $1500 \mathrm{~mm}$ column lengths. The position where the buckling occurred is encircled in red for each specimen. The failure mode was recorded for all specimens. The mean values of the maximum experimental load for each specimen length are presented in Table 2. These results are unexpected as there is not a significant difference between the first three column lengths with a range- of $71.44 \mathrm{kN}$ to $74.49 \mathrm{kN}$. The $300 \mathrm{~mm}$ specimens are classified as short columns, but the $600 \mathrm{~mm}$ and $900 \mathrm{~mm}$ columns were expected to have lower buckling resistance. This indicates that from $300 \mathrm{~mm}$ to $900 \mathrm{~mm}$ act similarly when subject to axial compression loads. The two longest columns (1200 $\mathrm{mm}$ and $1500 \mathrm{~mm})$ have a small range of $56.35 \mathrm{kN}$ to $57.73 \mathrm{kN}$ and act similarly in compression.

\section{Comparison Results}

The mean buckling loads obtained from experimental tests, Eurocode 3 buckling capacities, DSM buckling capacities, simplified FEM buckling loads and the finely refined imperfect FEM buckling loads are summarized for comparison in Table 2. No partial loading factors were considered in this study.

Table 2: Buckling Result Comparison

\begin{tabular}{|r|r|r|l|l|l|}
\hline $\begin{array}{l}\text { Specimen } \\
\text { Length }(\mathbf{m m})\end{array}$ & $\begin{array}{l}\text { Mean Experimental } \\
\text { Buckling Load (kN) }\end{array}$ & $\begin{array}{l}\text { Eurocode 3 } \\
\text { resistance Load } \\
(\mathbf{k N})\end{array}$ & $\begin{array}{l}\text { DSM resistance } \\
\text { Load (kN) }\end{array}$ & $\begin{array}{l}\text { Simplified FEM } \\
\text { Buckling Load } \\
(\mathbf{k N})\end{array}$ & $\begin{array}{l}\text { Fine FEM } \\
\text { Buckling Load } \\
(\mathbf{k N}) \text { - Imperfect }\end{array}$ \\
\hline 300 & 74.23 & 116.2 & 99.52 & 130.00 & 123.00 \\
\hline 600 & 74.49 & 102.88 & 90.45 & 120.00 & 119.27 \\
\hline 900 & 71.44 & 85.29 & 77.61 & 111.00 & 113.71 \\
\hline 1200 & 56.35 & 66.06 & 63.56 & 110.00 & 111.74 \\
\hline 1500 & 57.73 & 50.52 & 50.02 & 114.00 & 110.00 \\
\hline
\end{tabular}

The two FEA buckling loads are greater than the design based resistance values (Eurocode 3 and DSM), this is attributed to the fact that the FEA considers the non-linear section of the stress strain curve of the steel. In other words the FEAs 
considers the greater ultimate tensile strength $\left(\mathrm{f}_{\mathrm{u}}\right)$ of $371.45 \mathrm{MPa}$ for the steel and the code based buckling calculations are linear elastic which only considers the lower mean yield tensile strength $\left(\mathrm{f}_{\mathrm{y}}\right)$ of $300.34 \mathrm{MPa}$. The mean experimental loads, Eurocode 3 buckling capacities, DSM buckling capacities and both FEM buckling loads are plotted against the specimen length in Fig.6.

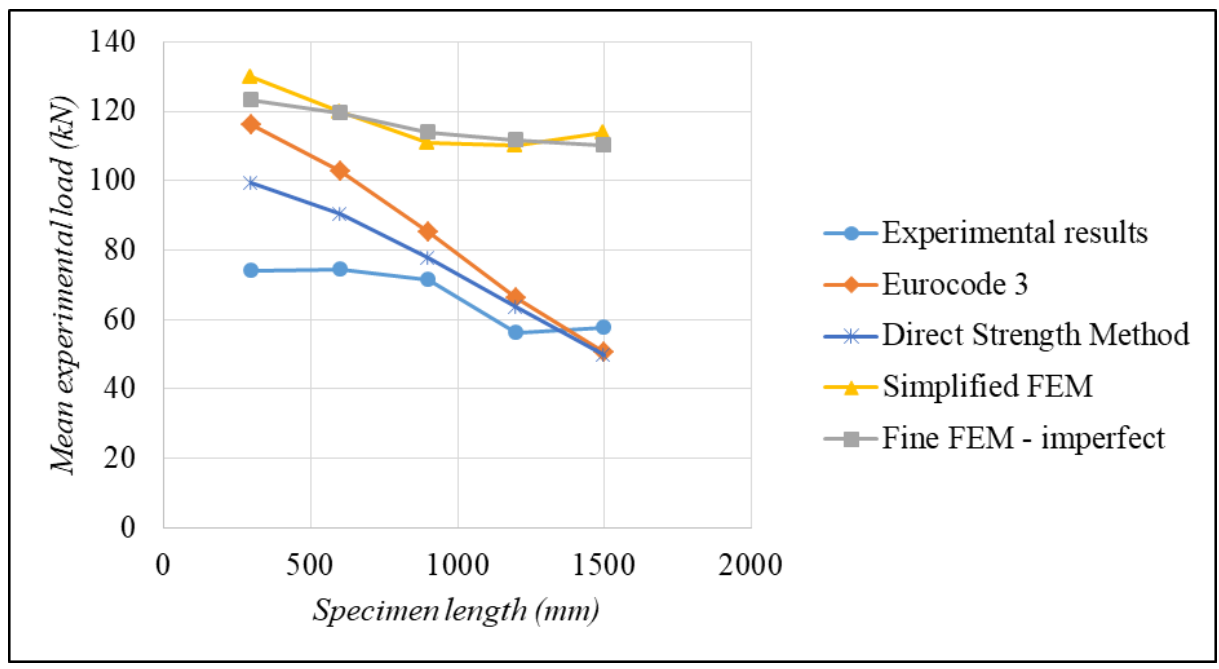

Fig. 6: Buckling Comparison

All five of the graphs have decreasing linear functions, with only the experimental results showing slight deviations for the $300 \mathrm{~mm}, 600 \mathrm{~mm}$ and $1500 \mathrm{~mm}$ specimens. The FEA shapes are similar to the experimental results, this indicates that the material behaves as expected but with lower capacity. The simplified and finely refined FEAs yield the greatest buckling resistance loads, the Eurocode 3 loads are more conservative, but the experimental results are much lower with the exception of $1500 \mathrm{~mm}$ specimen. The DSM buckling resistance loads are the closest to the experimental loads.

In order to quantify the difference between the experimental buckling loads from the various analysis methods, percentage difference between each of the analysis methods and the mean experimental buckling load were calculated. Only the Eurocode 3 and DSM buckling resistance values yielded one underestimation of the buckling load, with the resultant average difference yielding overestimation of $23.8 \%$ and $12.7 \%$ respectively. The simplified FEA overestimates the buckling load by $76.9 \%$ on average and the fine FEA overestimate the buckling load by $74.8 \%$ on average of the experimental capacity.

\section{Conclusion}

This paper investigated the buckling capacities of cold-formed lipped channel sections using five different methods: 1) experimental tests; 2) Eurocode 3; 3) SANS 10162-2 through the Direct Strength Method (DSM); 4) simplified Finite Element Analysis (FEA), i.e. only beam modelling elements; and 5) finely refined FEA, i.e. plate modelling elements. Five different column lengths were considered in the quantitative research. The results of the study are in agreement with the research conducted by West-Russell et al. [24] who recommended that different capacity reduction factors should be applied for cold-formed steel columns. It is recommended that the Direct Strength Method (DSM), should be used to calculate the buckling resistance of cold-formed lipped channels with different capacity reduction factors. The relevant values of the capacity reduction factors is a proposed topic for future studies. A more detailed investigation into the structural resistance of thin-walled steel sections subject to axial loading is required, if Eurocode 3 is to be adopted in South Africa. Currently, existing research is lacking that integrates the Eurocode 3 standard to South African conditions for cold-formed steel design. 


\section{References}

[1] B.W. Schafer, "Designing cold-formed steel using the direct strength method," in Eighteenth International Specialty Conference on Cold-Formed Steel Structures: Recent Research and Developments in Cold-Formed Steel Design and Construction, Orlando, FL, 2006, pp. 475-488.

[2] Y. Shifferaw, L.C.M. Vieira, and B.W. Schafer, "Compression testing of cold-formed steel columns with different sheathing configurations," in Annual Stability Conference: Reports on Current Research Activities, Orlando, FL, 2010, pp. 593-612.

[3] The structural use of steel Part 2 : Cold-formed steel structures, SANS 10162-2, South African Bureau of Standards, Pretoria, 2011.

[4] M.A. West-Russell, C. Viljoen, and E. van der Klashorst, "An assessment of the inherent reliability of SANS 10162-2 for cold-formed steel columns using the direct strength method." in Life-Cycle Analysis and Assessment in Civil Engineering: Towards an Integrated Vision - Proceedings of the 6th International Symposium on Life-Cycle Civil Engineering, (March), Ghent, Belgium, 2018, pp. 2601-2605.

[5] Basis of Structural Design and actions for buildings and industrial structures, SANS 10160-1, South African Bureau of Standards, Pretoria, 2010.

[6] A. Bauer, "The Reliability Margin of the Direct Strength Method Prediction Model for Cold-Formed Steel Members", Unpublished master's thesis. Stellenbosch, 2016.

[7] M. Dundu, "Buckling of short cold - formed lipped channels in compression," Journal Of The South African Institution of Civil Engineering, vol. 56(2), pp. 46-53, 2014.

[8] The Red Book, The Southern African Steel Construction Handbook, 8th Edition. Johannesburg: Southern African Institute of Steel Construction, 2013.

[9] J. Ye, I. Hajirasouliha, and J. Becque, "Experimental investigation of local-flexural interactive buckling of cold-formed steel channel columns," Thin-Walled Structures, vol. 125, pp. 245-258, 2018. doi: 10.1016/j.tws.2018.01.020

[10] Continuous hot-dip zinc-coated and zinc-iron alloy-coated carbon steel sheet of structural quality. SANS 4998, South African Bureau of Standards, Pretoria, 2014.

[11] Eurocode 3: Design of steel structures - Part 1-1: General rules and rules for buildings, EN 1993-1-1, European Committee for Standardization (CEN), Brussels, 2009.

[12] Z. Li and B.W. Schafer, "Buckling analysis of cold-formed steel members with general boundary conditions using CUFSM: Conventional and constrained finite strip methods," in 20th International Specialty Conference on ColdFormed Steel Structures - Recent Research and Developments in Cold-Formed Steel Design and Construction, Saint Louis, Missouri, 2010, pp. 17-31.

[13] B.W. Schafer, Direct Strength Method (DSM) Design Guide. Washington DC: American Iron and Steel Institute, 2006.

[14] Eurocode 3: Design of steel structures - Part 1-5: Plated structural elements, EN 1993-1-5, European Committee for Standardization (CEN), Brussels, 2009.

[15] L. Gardner, Designers' Guide to Eurocode 3: Design of Steel Buildings, 2nd edition. doi: 10.1680/dsb.41721. London: Institution of Civil Engineers, 2011.

[16] Eurocode 3: Design of steel structures Part 1-3: General rules - Supplementary rules for cold-formed members and sheeting, EN 1993-1-3, European Committee for Standardization (CEN), Brussels, 2009.

[17] The structural use of steel Part 1 : Limit-states design of hot-rolled steelwork, SANS 10162-1, South African Bureau of Standards, Pretoria, 2011.

[18] M. Holický, Reliability analysis for structural design, first edition, Stellenbosch: Sun Press, 2009. doi: 10.18820/9781920689346.

[19] D. Ungermann, S. Lübke, and B. Brune, "Tests and design approach for plain channels in local and coupled localflexural buckling based on eurocode 3," Thin-Walled Structures. Elsevier, 81, pp. 108-120, 2014. doi: 10.1016/j.tws.2013.09.013.

[20] Standard test methods for tension testing of metallic materials 1, ASTM E8/E8M (American Society for Testing and Materials), Annual Book of ASTM Standards 4, (C), pp. 1-27. doi: 10.1520/E0008. 2010. 
[21] C.C. Weng, and T. Pekoz, "Compression tests of cold-formed steel columns," Journal of structural engineering New York, vol. 116(5), pp. 1230-1246, 1990. doi: 10.1061/(ASCE)0733-9445(1990)116:5(1230).

[22] J.M. Gere and B.J. Goodno, Mechanics of Materials, 7th Edition, Toronto: Cengage Learning, 2017.

[23] R.C. Hibbeler, Mechanics of Materials, 9th Edition, Cape Town: Prentice Hall, 2014.

[24] R. Basan, "Study on Ramberg-Osgood and Chaboche models for 42CrMo4 steel and some approximations," Journal of Constructional Steel Research, vol. 136(May), pp. 65-74, 2017. doi: 10.1016/j.jcsr.2017.05.010.

[25] P. Deolia and F.A. Shaikh, "Finite element analysis to estimate burst pressure of mild steel pressure vessel using Ramberg-Osgood model," Perspectives in Science. Elsevier GmbH, vol. 8, pp. 733-735, 2016. doi: 10.1016/j.pisc.2016.06.073.

[26] R.E. Walpole, R.H. Myers, S.L. Myers, and K.E. Ye, Probability \& Statistics for Engineers \& Scientists. $9^{\text {th }}$ Edition. Virginia: Prentice Hall, 2012. 